\title{
Children and Scientific Observations: Pupils Measuring Greylag Goose Behaviour
}

\author{
Frigerio Didone $^{1} \quad$ Kurt Kotrschal $^{1,2} \quad$ Eva Millesi $^{2} \quad$ Josef Hemetsberger $^{1,2}$ \\ ${ }^{1}$ Core Facility 'Konrad Lorenz Forschungsstelle' for Behaviour and Cognition, University of \\ Vienna, Fischerau 11, A-4645 Gruenau im Almtal, Austria \\ ${ }^{2}$ Department of Behavioural Biology, University of Vienna, Althanstrasse 14, A-1090 Vienna, \\ Austria
}

\begin{abstract}
Recent scientific research provides increasing evidence for the importance of promoting scientific skills even among children. In the present study, a total of 110 primary school pupils from three different grades (first to third, 6-10 years of age) and seven different classes were involved in an observational scientific project about the behaviour of a highly social bird, the Greylag goose (Anser anser). The semi-tame flock of the Core Facility "Konrad Lorenz Forschungsstelle" for Behaviour and Cognition - University of Vienna offers a unique opportunity for school-children to work with freeliving animals. It consists of around 140 free-flying and individually marked geese, which are habituated to the close presence of humans. Here, we focussed on the children's capability of collecting behavioural data in a reliable and standardized way. The goal was to determine whether the pupils could be actively involved in the collection of such behavioural data. The pupils were instructed and trained at school as well as in the field on how to observe Greylag goose behaviour. Their reliability was tested using analyses of video sequences with a group of professional behavioural biologists as control. The results showed no significant differences between the performance of pupils and professional biologists, confirming the children's enormous potential to be reliable observers in animal behaviour research.
\end{abstract}

\section{Introduction}

Scientific research has provided increasing evidence confirming the importance of early positive nature experience as well as the need for contact to nature and animals, especially for humans living in urbanized environments [e.g. 1, 2, 3, 4].

More than 20 years ago, Konrad Lorenz suggested the fundamental role of an emotional bond between an animal (the Greylag goose, Anser anser) and a child to motivate children's participation in the scientific study of the geese. The underlying goal was to "raise awareness for the fact that humans are not the only living beings with feelings and experience on our planet" [5]. In more recent years, various studies confirmed the benefits of promoting scientific thinking among children [6, 7]. Indeed, science has the potential to change everyone's approach to the world. R.B. Lotto (2010), for instance, recently showed how reliably primary school pupils can be involved in scientific research [8].

In the present study, we used the fresh inquiring minds of primary school children to involve them in a scientific project of age-adequate dimensions. This was done in the framework of the research program Sparkling Science funded by the Austrian Federal Ministry of Science and Research, which promotes and supports scientists working side by side with young people in the kind of scientific research, which yields results publishable under peer review. This way, the Core Facility "Konrad Lorenz Forschungsstelle" for Behaviour and Cognition University of Vienna (KLF) started two-year collaboration with two local primary schools. The scientific aim of the project was to investigate seasonal behavioural differences between male and female greylag geese. Such a dataset is part of the long-term monitoring of the KLF and will be published elsewhere. Another aim was to see whether young pupils could be reliable scientific observers. Here, we aim to concentrate at the latter question and to show that pupils can be actively involved in data collection in animal behaviour research. Primary school children were trained at school as well as in the field on how to correctly observe Greylag goose behaviour. Their reliability was then tested using video. A group of professional behavioural biologists familiar with goose behaviour voluntarily served as a control coders.

\section{Materials and Methods}

\section{Animals and Study Site}

The non-migratory flock of Greylag geese was introduced into the valley of the Alm River in Upper Austria by Konrad Lorenz and co-workers in 1973 [9] at the Konrad Lorenz Forschungsstelle, now Core Facility of the University of Vienna (www.klf.ac.at). Today, the flock consists of about 140 free-flying 
birds. These birds rival social mammals in social complexity [10], but with easily observable behaviour. All individuals are marked with a unique combination of coloured leg rings and are habituated to the close presence of humans. They do not show avoidance behaviour or any stress response when familiar humans approach $[11,12]$. Life history data and social backgrounds of all individuals have been monitored continuously since 1973 [13]. Therefore, the flock offers a unique opportunity for schoolchildren to work with free-living animals.

\section{Partner schools}

Two local primary schools were involved in the project, the first one from the village where the research station is located (Gruenau im Almtal) and the second one from a neighbouring village (Muehldorf). In total, 110 pupils from three different grades (first to third) and seven different classes participated in the project (Table 1).

Table 1. Schools and pupils involved in the project. ${ }^{*} \mathrm{G}=$ Gruenau, $\mathrm{M}=$ Muehldorf.

\begin{tabular}{|c|c|c|c|c|}
\hline $\begin{array}{c}\text { School } \\
\text { year }\end{array}$ & School $^{*}$ & Grade & $\begin{array}{c}\text { Pupils } \\
\text { N }\end{array}$ & $\begin{array}{c}\text { Pupils' } \\
\text { age }\end{array}$ \\
\hline $2010 / 11$ & G & 2nd & 17 & $7-9$ \\
\hline & G & 3rd & 23 & $8-10$ \\
\hline $2011 / 12$ & G & 1st a & 14 & $6-8$ \\
\hline & G & 1st b & 13 & $6-8$ \\
\hline & G & 2nd & 13 & $7-9$ \\
\hline & M & 2nd a & 15 & $7-9$ \\
\hline & M & 2nd b & 15 & $7-9$ \\
\hline
\end{tabular}

\section{Pupils Training}

The work plan with the children included two training phases termed "recognizing the geese" and "establishing an ethogram". These phases were divided into four sometimes simultaneous steps including a theoretical part at school, a training part in the field, a control step and finally the integration in the behavioural project. The control step involved professional biologists of the KLF as a control group.

First, the pupils learned how to individually recognize the geese by using the goose-list, in which all geese are tabulated by name and coloured ring combination. Subsequently, an ethogram (i.e. series of individual behavioural entities) showed them how to discriminate between different behaviours. These goals were achieved through "learning by playing" with different riddles. The entire material was available in the schools at all times. To motivate the pupils, a "researcher-pass" was introduced, in which the children could collect stamps by solving one of the outlined tasks. The methodological details of this part of the project will be published elsewhere.

The theory, learned at school on paper, was put into practice in the field. The pupils visited the KLF once per month during school-time, and the visits were scheduled to avoid extremely unfavourable weather, like heavy rain or snow. Throughout the school year, each class visited the Greylag geese at the KLF between 7 and 8 times, starting in OctoberNovember until May-June. The same tasks taught at school awaited the pupils in the field. Based on the teachers' decision, the children worked in small teams of 2 to 3 pupils.

\section{Pupils' test using video}

After the training phase, the pupils entered the control step in which both tasks - the capability to correctly read the goose list and to recognize goose behaviour - were tested. As far as the goose list is concerned, the children were tested in small groups on site and none of them made any errors (Frigerio, personal observations). We therefore concentrated on testing the behavioural observations. Because of logistics and time constraints it was impossible to closely survey pupils' performances in the field. We therefore used video sequences for this analysis. Each class was shown the same three video sequences and asked to record the behaviour of the focal goose displayed in the clip by scan sampling it in 30-s intervals. Each sequence lasted 5 minutes. Between the second and the third video, the pupils were training again in the field. Each test was scheduled on a different day within a two-week period in February. At that time, the pupils were familiar with the behavioural protocol as well as with the sampling method. The same three videos were shown to a group of professional behavioural biologists working daily at the KLF with greylag geese as well other avian species (crows, ravens). The 30-s sampling intervals were loudly communicated by the principal investigator (DF) for both groups. Each pupil or biologist worked alone. Specifically, the pupils of the first grade used a simplified protocol, whereas the pupils of the upper grades wrote their observations in the very same protocol sheet as the biologists.

\section{Data analysis}

Video data were first analysed assuming DF's observations as "correct" for observer groups, pupils as well as biologists. The individual percentage of correct observations per video per observer group was calculated and used for further analysis.

Secondly, data were analysed looking at the individual observation per se. Out of several 
behavioural parameters included in the Greylag goose's ethogram, two were chosen for further analysis: (1) foraging behaviour, including feeding and drinking [9] and (2) vigilance behaviour, specifically "head up" [14]. The percentage of the frequency of occurrence per protocol was recorded for both considered behavioural parameters and used for further analysis.

Residuals were not normally distributed (Kolmogorov Smirnov: individual percentages of correct observations: $n=312, Z=3.979, p \leq 0.000$; individual records of foraging behaviour: $n=312, Z$ $=3.979, p \leq 0.000$; individual records of vigilance behaviour: $n=312, Z=3.979, p \leq 0.000$ ). Therefore, non-parametric statistical tests were applied (SPSS 11.5 statistical software; SPSS Inc., Chicago, IL, USA). Results of all tests are given two-tailed; levels of significance were corrected according to Bonferroni post hoc test whenever necessary [15].

\section{Results}

The mean percentages of correct observations for both groups, pupils and biologists, were similar (Table 2).

Table 2. Mean percentages of correct observations from videos per group of observers.

\begin{tabular}{|c|c|c|}
\hline Video & Pupils & Biologists \\
\hline $1^{\text {st }}$ & 82.00 & 92.07 \\
\hline $2^{\text {nd }}$ & 82.07 & 90.91 \\
\hline $3^{\text {rd }}$ & 93.16 & 96.97 \\
\hline
\end{tabular}

Plotting all the pupils together, including the first graders, revealed no significant differences in the individual percentage of correct observations to the control group (Mann-Whitney: $1^{\text {st }}$ video $U=137.0$, $n_{\text {pupils }}=101, n_{\text {biologists }}=5, p \leq 0.231 ; 2^{\text {nd }}$ video $U=$ $146.5, n_{\text {pupils }}=97, n_{\text {biologists }}=6, p \leq 0.118 ; 3^{\text {rd }}$ video $U$ $=222.0, n_{\text {pupils }}=97, n_{\text {biologists }}=6, p \leq 0.864$; Fig. 1 ).

When comparing within grades, we did find differences depending on the age of the children (Kruskal Wallis: $1^{\text {st }}$ video $\chi^{2}=46.7, d f=3, p \leq$ $0.000, n_{1 \text { st grade }}=25, n_{2 \text { nd } \text { grade }}=57, n_{3 \text { rd grade }}=19$, $n_{\text {biologists }}=5 ; 2^{\text {nd }}$ video $\chi^{2}=23.734, d f=3, p \leq 0.000$, $n_{\text {lst grade }}=24, n_{2 n d \text { grade }}=56, n_{3 r \text { grade }}=17, n_{\text {biologists }}=$ $6 ; 3^{\text {rd }}$ video $\chi^{2}=11.17, d f=3, p \leq 0.066, n_{\text {lst grade }}=$ $24, n_{2 n d \text { grade }}=56, n_{3 \text { rd grade }}=17, n_{\text {biologists }}=6$; Fig. 2 ). The statistical difference is mainly caused by the youngest age class, which made fewer correct observations than the older children (Fig. 2). Excluding them leads to non-significant differences within the pupils (Mann-Whitney: $1^{\text {st }}$ video $U=$ $398.5, n_{2 n d \text { grade }}=57, n_{3 r d \text { grade }}=19, p \leq 0.204 ; 2^{\text {nd }}$ video $U=343.0, n_{2 n d \text { grade }}=56, n_{3 r d \text { grade }}=17, p \leq$ $0.219 ; 3^{\text {rd }}$ video $U=341.0, n_{2 n d \text { grade }}=56, n_{3 r d}$ grade $=$ $17, p \leq 0.177)$.

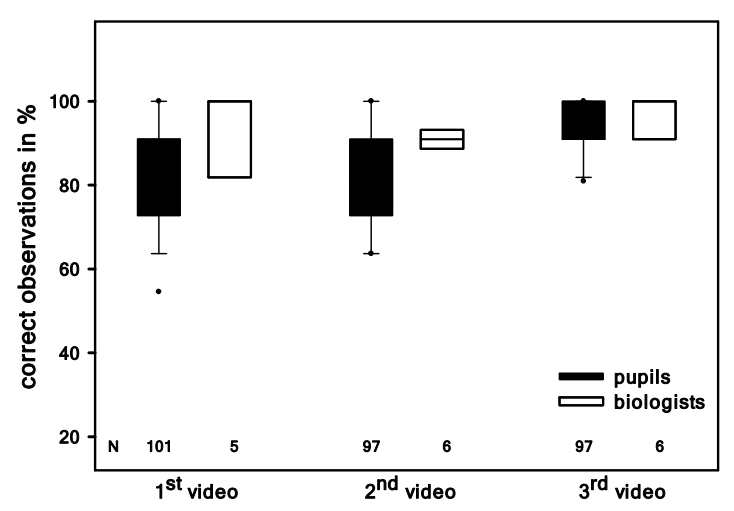

Figure 1

Mean percentage of correct observations of pupils and biologists during behavioural recording of 3 video clips. Full lines median and inter-quartile ranges; whiskers range between 10th and 90th percentile; full circles data outside 10 th and 90 th percentile.

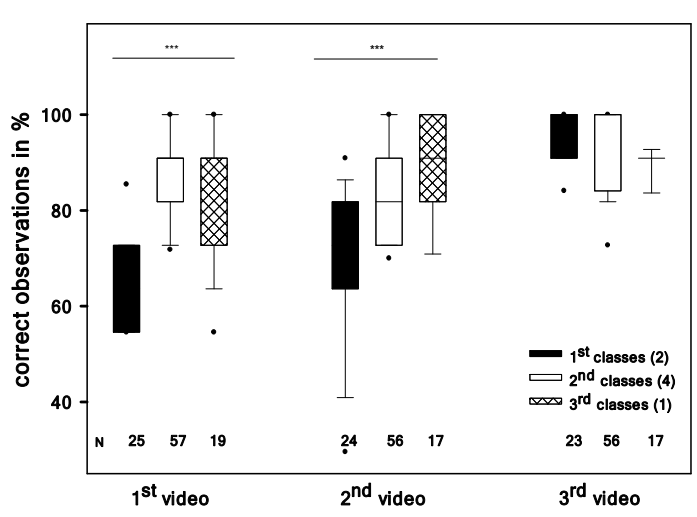

Figure 2

Comparison of performances (percentage of correct observations) between different age groups (first, second and third grade) among pupils. Full lines median and inter-quartile ranges; whiskers range between 10th and 90th percentile; full circles data outside 10th and 90th percentile.

When analysing behavioural observations from videos, significant differences between pupils and biologists in recording foraging behaviour were found only in the first video (Mann-Whitney: $1^{\text {st }}$ video $U=3.0, n_{\text {pupils }}=75, n_{\text {biologists }}=6, p \leq 0.000 ; 2^{\text {nd }}$ video $U=227.5, n_{\text {pupils }}=72, n_{\text {biologists }}=7, p \leq 0.536$; $3^{\text {rd }}$ video $U=247.0, n_{\text {pupils }}=72, n_{\text {biologists }}=7, p \leq$ 0.917; Fig. 3). Pupils recorded higher frequencies of foraging behaviour than the biologists (Fig. 3). 
Another significant difference between pupils and biologists was found in the recorded vigilance behaviour from the first video clip. In this case, pupils recorded lower frequencies of such behaviour than the control group (Mann-Whitney: $1^{\text {st }}$ video $U=$ $24.5, n_{\text {pupils }}=75, n_{\text {biologists }}=6, p \leq 0.000 ; 2^{\text {nd }}$ video $U$ $=113.5, n_{\text {pupils }}=72, n_{\text {biologists }}=7, p \leq 0.084 ; 3^{\text {rd }}$ video $U=252.0, n_{\text {pupils }}=72, n_{\text {biologists }}=7, p \leq 1.0$; Fig. 4). No significant differences between the groups were found in the second and third video.

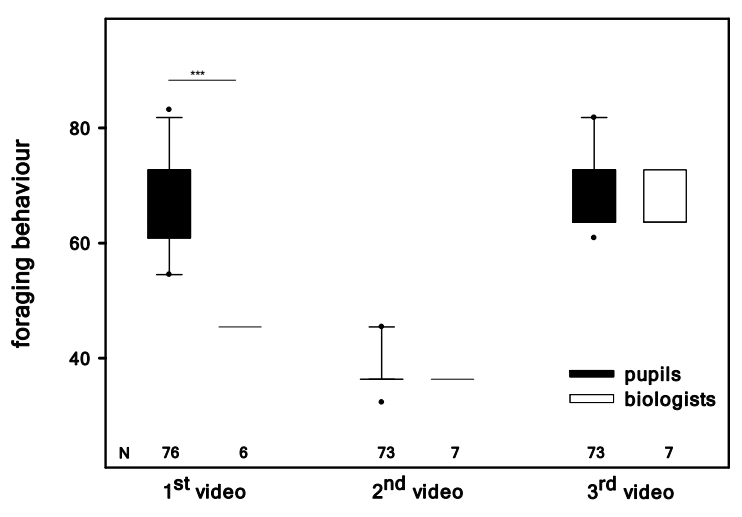

Figure 3

Comparison of the results between pupils and biologists recording frequencies of foraging behaviour from 3 video clips. Full lines median and inter-quartile ranges; whiskers range between 10th and 90th percentile; full circles data outside 10th and 90th percentile.

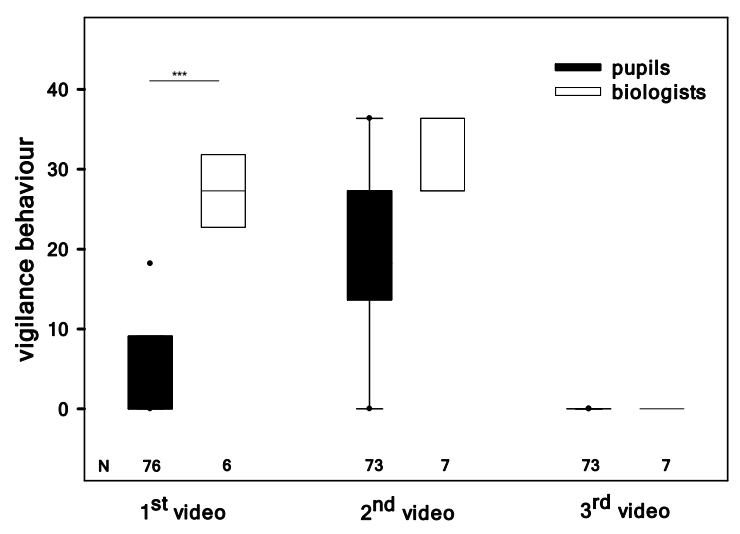

Figure 4

Comparison of the results between pupils and biologists recording frequencies of vigilance behaviour from 3 video clips. Full lines median and inter-quartile ranges; whiskers range between 10th and 90th percentile; full circles data outside 10th and 90th percentile.

\section{Discussion}

Our data remarkably suggest that well-trained children can reliably observe animal behaviour. The children's percentage of correct observations is increasing from one video to the next, which may suggest a role of experience in learning how to correctly observe an animal from video (Tab. 2; Fig. 1). Although the differences among the three videos may reflect different difficulty grades, these played apparently no role. Among the three videos, the second one was the most difficult because the focal goose was moving around a lot and getting marginally involved in interactions with other geese. Such behaviours imply a bigger effort not to lose the animal while writing the protocol. Nonetheless, the mean percentage of correct observations over the three videos was $85 \%$. This is an excellent performance and did not differ significantly from professional biologists highly trained in observing goose behaviour.

The first grade pupils performed differently compared to the other grades involved in the project. Such differences could be age-dependent, as these pupils tended to be the youngest ones. Pupils' age is overlapping between the previous and the next grade (Tab. 1), therefore different grades could take in pupils of the same age. However since the percentage of correct observations in the third video were similar to the other age classes, we rather suggest a role of scholarship or education. In fact, in the Austrian school system, at the beginning of the project the first graders could neither read nor write and were learning it in the same period they were training for the goose project. Accordingly, learning to write and read might have had a major priority over the training for the goose project. In fact, the school-time set apart for training for the goose project was based on teacher's decision.

Another possible explanation for the observed difference between the first and the upper grades could be the different protocol used for these children. This was simplified by using pictures of the goose behavioural parameters. Nonetheless, the results of the third video shows that first grade pupils can become as good observers as professional biologists.

A preliminary dataset, presented as a poster for the London International Conference on Education 2011 [16] did show grade-dependent differences in the records of the behavioural parameters in the first video. Such results are confirmed by the present work. Nonetheless, we consider all the pupils as a unit and suggest that one or two additional videos would improve the pupils' performances considerably.

Furthermore, choosing professional behavioural biologists as a control group and comparing their performances with those of the pupils' could be 
judged as "unfair" because none of the pupils actively chose to be an ethologist: this might be reflected in different motivation levels between the groups. For future projects with similar topics, we would suggest to consider biology students in their first university semester as a control group.

Despite these potential problems, the results underline the pupils' enormous potential for reliable observations in the frame of a scientific project.

In any case, involving pupils in scientific research is advantageous in many respects, both on a longand short-term scale. On a long-term scale, we educate future adults to approach natural phenomena in a scientific manner; over the short term, we gain acceptance among the public, potentially leading to increased support and funding of scientific research projects.

Finally, pupils profit from such an activity, not only by gaining insight into the scientific approach and way of thinking, but also because they gain several other learning skills. Children learned how to respectfully interact with semi-tame wild animals and, in some cases, to cope with or overcome their fear. By working in small groups, they experienced collaborating in a team, taking responsibility for a part of the task and trusting their colleagues for their inputs. Moreover, they learned how to fully concentrate on one task, namely observing a goose.

\section{Acknowledgements}

The project was funded by the "Sparkling Science" research program of the Austrian Federal Government Department of Science and Research (BMWF; SPA/03-005/Graugänse). Further financial support came from the Department of Behavioural Biology of the University of Vienna and the local company Mayr Schulmöbel. Permanent support comes from the Herzog von Cumberland Stiftung as well as from the Verein der Förderer der Konrad Lorenz Forschungsstelle. We are grateful to A. Bisenberger, S. Ludwig, I. Scheiber, B. Weiß, and the colleagues of the KLF for their valuable contributions to the project. A. Braun, L. Cibulski, S. Ludwig, I. Scheiber and S. Schmiding agreed in joining the control group. Thanks to M. Stachowitsch for his comments on the manuscript. Special thanks for their collaboration to the directors and teachers of the Primary Schools of Gruenau im Almtal and Muehldorf (municipality Scharnstein), S. Schiefermair, E. Staudinger, R. Wittmann, B. Leberbauer, A. Merschitzka, E. Rotky, M. Geisbauer, K. Steinkogler as well as to their pupils: M. Amering, S. Bammer, H. Birthelmer, M. Hemetsberger, L. Huemer, A. Leithinger, J. Leithinger, S. Mayrhofer, L. Mitterhauser, T. Mizelli, M. Pesl, L. Retschitzegger, L. Straßer, K. Strasser, C. Stummer, M. Weidinger, D. Wolf, F. Ahamer, B. Bajraktari, E. Bogdan, N. Brozek, M.
Burgstaller, S. Drack, V. Ettinger, A. Ferstl, J. Fischer, E. Merschitzka, M. Merschitzka, P. Mitterlehner, A. Mittermayr, J. Mobbs, M. Moser, C. Obayagbon, B. Rauscher, V. Redl, S. Rubasch, A. Weissensteiner, T. Wolf, J. Hauer, L. Graef, P. Holzinger, F. Kefer, E. Maliqi, R. Mayrhofer, H. Odman, C. Redl, A. Schoiswohl, R. Tiefenthaler, A. Wagner, N. Wallner, V. Wittmann, C. Pesl, K. Hauer, L. Kuntner, S. Schachinger, A. Huemer, A. Leithinger, C. Straßer, E. Geishüttner, E. Seidel, L. Auinger, M. Urferer, M. Eckart, S. Götzendorfer, J. Bieregger, I. Drack, J. Drack, E. Eckhart, K. Heikenwälder, K. Kreiseder, N. Linsmeyer, L. Luckerbauer, N. Odman, F. Redl, K. Stadler, J. Traußnig, A. Zauner, A. Besic, A. Fürtbauer, L. Lasch, N. Mairhofer, M. Moser, M. Pirzl, J. Raffelsberger, C. Rauscher, M. Rinnerberger, K. Sadleder, Z. Schachermayr, M. Silmbroth, A. Stadler, E. Strasser, L. Wöger, J. Buchegger, N. Derflinger, K. Ebenführer, T. Feßl, M. Fürtbauer, A. Gavric, E. Gegendorfer, D. Gruber, F. Hartleitner, E. Hüthmayr, A. Platzer, H. Schellmann, J. Trautmann, E. Winter, T. Wittmann.

\section{References}

[1] Bisenberger, A. and Frigerio, D. (2012) „Biene Maja zeigt uns ihre Welt - von einer Projektidee zur angewandten Methodik tiergestützter Vermittlungsarebit mit Kleintieren“, Öko-L 2, pp.29-35.

[2] Louv, R. (2011) „Das letzte Kind im Wald?“, Beltz Verlag Weinheim and Basel.

[3] Wedl, M. and Kotrschal, K. (2009) „Social and individual component of animal contact in preschool children “Anthrozoös 22 (4), pp. 383-396.

[4] Otterstedt, C. (2007) „Mensch und Tier im Dialog“, Kosmos Verlag Stuttgart.

[5] Lorenz, K. (1986) in „Das Gänse Kinderbuch“ by S. Kalas, Findling Bücher Verlag Lüneburg.

[6] Elschenbroich, D. (2005) „Weltwunder - Kinder als Naturforscher", Kunstmann Verlag München.

[7] Wagenschein, M. (2002), Erinnerungen für morgen. Eine pädagogische Autobiographie“"Weinheim Verlag.

[8] Blackawton, P. S., Airzee, S., Allen, A., Baker, S., Berrow, A., Blair, C., Churchill, M., Coles, J., Cumming, R. F.-J.,Fraquelli, L., Hackford, C., Hinton Mellor, A., Hutchcroft, M., Ireland, B., Jewsbury, D., Littlejohns, A., Littlejohns, J. M., Lotto, M., McKeown, J., O’Toole, A., Richards, H., Robbins-Davey, L., Roblyn, S., RodwellLynn, H., Schenck, D., Springer, J., Wishy, A., RodwellLynn, T., Strudwick, D. and Lotto, R.B.(2011)

"Blackawton bees" Biology Letters 7 (2), pp. 168-172.

[9] Lorenz, K. (1988) „Hier bin ich-wo bist du? Ethologie der Graugans" Piper Verlag, Munich Germany. 
[10] Kotrschal, K., Scheiber, I.B.R. and Hirschenhauser, K.(2010) "Individual Performance in Complex Social Systems: The Greylag Goose Example" In: Animal Behaviour: Evolution and Mechanisms. P. Kappeler (ed.) pp. 121-148. Springer Verlag Berlin.

[11] Wascher, C.A.F., Fraser, O.N. and Kotrschal, K. (2010) "Heart Rate during Conflicts Predicts Post-Conflict Stress-Related Behavior in Greylag Geese" PLOS ONE 5(12): e15751. doi:10.1371/journal.pone.0015751.

[12] Scheiber, I.B.R., Weiß, B.M., Frigerio, D. and Kotrschal, K. (2005) "Active and passive social support in families of Greylag geese (Anser anser)" Behaviour 142, pp. 1535-1557.

[13] Hemetsberger, J. (2001) „Die Entwicklung der Grünauer Graugansschar seit 1973“ In: Konzepte der Verhaltensforschung. Konrad Lorenz und die Folgen (ed. by K. Kotrschal, G. Müller and H. Winkler). Fürth: Filander Verlag

[14] Lazarus, J. (1978) "Vigilance, flock size and domain of danger size in the white-fronted goose" Wildfowl 29, pp. 135-145.

[15] Rice, W.R. (1989) “Analyzing tables of statistical tests" Evolution 43, pp. 223-225.

[16] Frigerio, D., Kotrschal, K., Millesi, E., Hemetsberger, J., (2011) "Pupils as Ethologists? Comparison between Elementary School Pupils' and Biologists' Behavioural Observations of Free-Living Greylag Geese (Anseranser)". Proc. LICE-2011, pp. 121-122. 